\title{
Arranjos produtivos locais como estratégia neodesen- volvimentista e o papel da qualificação profissional
}

\author{
Local productive arrangements as neo-developmentalist \\ strategy and the role of professional training
}

Fabiana Costa*

Angela Amaral**

\begin{abstract}
Resumo - O presente artigo pretende discutir as políticas voltadas à qualificação profissional dos trabalhadores do Arranjo Produtivo Local de Confecções de Pernambuco, assim como analisar o conteúdo ídeopolítico que as fundamenta. Expõe as formas como estas políticas ganham relevo na dinâmica capitalista contemporânea, em particular na Região Nordeste, configurando-se como uma estratégia compatível com o discurso e as diretrizes do contexto neodesenvolvimentista brasileiro. Apresenta o cenário de crescimento econômico convivendo com a ampliação da informalidade, da precarização e da superexploração do trabalho. Conclui que as práticas de qualificação desenvolvidas têm um caráter instrumental cujo objetivo é a aquisição de competências individuais, o "saber-fazer" e a formação de empreendedores na região.
\end{abstract}

Palavras-chave: qualificação profissional; arranjos produtivos locais; neodesenvolvimentismo.

\begin{abstract}
The following paper aims to discuss policies oriented towards the professional training of workers at the local productive arrangement in Pernambuco, and to assess the ideological-political content underlying such policies. It exposes the ways by which these policies take center stage in contemporary capitalist dynamics, particularly in the Brazilian Northeast, and thus configures itself as a strategy compatible with the discourse and directives of Brazilian neo-developmentalist moment. It presents a scenario of economic growth that coexists with growing informality, precariousness, and overexploitation. Finally, it concludes that the current professional training policies have an instrumental character: the pursuit of individual skills and the training of local entrepreneurs.

Keywords: professional training; local productive arrangements; neodevelopmentalism.
\end{abstract}

\footnotetext{
* Mestre em serviço social pela Universidade Federal de Pernambuco (UFPE). Assistente Social da Universidade Federal Rural de Pernambuco (UFRPE). Correspondência: Av. Bom Pastor, s/n, Boa Vista, Garanhuns/PE. CEP: $55292-$ 270. Email: <fabiana.mkosta@gmail.com>

** Doutora em Serviço Social pela Universidade Federal do Rio de Janeiro (UFRJ). Professora Adjunta do Departamento de Serviço Social da Universidade Federal de Pernambuco (UFPE). Vicer-líder do Grupo de Estudos e Pesquisas sobre Trabalho (GET). Correspondência: Avenida dos Economistas, s/n- Cidade Universitária, Recife/PE. CEP: 50670901. Email:<angelaufpe@yahoo.com.br>
} 
\} ARRANJOS PRODUTIVOS LOCAIS COMO ESTRATÉGIA NEODESENVOLVIMENTISTA - COSTA, F.; AMARAL, A. \} DOI: $10.12957 /$ rep.2015.21050

\section{Introdução}

O presente artigo apresenta resultados da pesquisa de mestrado do Programa de Pós-Graduação da Universidade Federal de Pernambuco (UFPE), cujo objetivo foi analisar as ações voltadas à formação profissional dos trabalhadores do Arranjo Produtivo Local de Confecções de Pernambuco, conhecido como Polo de Confecções do Agreste ${ }^{1}$, especialmente do município de Toritama, assim como o conteúdo ídeo-político que as fundamenta.

A proposta dos Arranjos Produtivos Locais (APL), no Brasil, foi inspirada no modelo dos distritos industriais italianos localizados no sul do país - uma forma de enfrentamento da crise que a Itália atravessava e como alternativa de romper com o modelo das grandes corporações e da competitividade. Balizada nas noções de pequena empresa, cooperação, inovação, conhecimento e território, o êxito de tais arranjos se justifica pelas inovações no processo produtivo, aliado à competitividade, à flexibilidade e ao investimento no capital cognitivo.

Na particularidade brasileira, o APL é definido pelo Serviço Brasileiro de Apoio às Micro e Pequenas Empresas (SEBRAE, 2012, p. 8) como uma

aglomeração de empresas localizadas em um mesmo território, que apresenta especialização produtiva e mantém algum vínculo de articulação, interação, cooperação e aprendizagem entre si e com outros atores locais, tais como: governo, associações empresariais, instituições de crédito, ensino e pesquisa.

Trata-se de uma proposta de política industrial que também é incorporada como política pública de estímulo ao desenvolvimento regional. Nos documentos oficiais, essa proposta é delineada como uma experiência desenvolvimentista para países em desenvolvimento, principalmente pela sua promessa de combinar ações econômicas com melhorias sociais, sendo capazes de proporcionar dinamismo nas economias locais, gerando renda e desenvolvimento social na realidade em que se situa.

Na primeira década dos anos 2000, os discursos, por parte de instituições governamentais e não governamentais, que apresentam a importância dos APLs como mecanismo de desenvolvimento socioeconômico, são cada vez mais frequentes. Além disso, ganham força material em virtude dos elementos econômicos, políticos, culturais e ideológicos que mobilizam como parte constitutiva de uma agenda neodesenvolvimentista, a qual se difunde nos governos Lula da Silva e Dilma Rousseff, em particular.

\footnotetext{
1 O Polo de Confecções, na região Agreste de Pernambuco, de acordo com o Sindicato da Indústria de Vestuários de Pernambuco (Sindvest), é formado por oito municípios: Caruaru, Toritama, Santa Cruz do Capibaribe, Cupira, Riacho das Almas, Surubim, Agrestina e Taquaritinga do Norte, que desenvolvem a produção têxtil e de confecção, sendo o segundo maior produtor de confecções do país.
} 


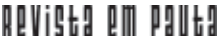

\} ARRANJOS PRODUTIVOS LOCAIS COMO ESTRATÉGIA NEODESENVOLVIMENTISTA - COSTA, F.; AMARAL, A. \} DOI: $10.12957 /$ rep.2015.21050

Em Pernambuco, a criação de APL tem sido alvo de atenções de agentes públicos e privados pela forma como é articulada a produção de mercadorias, pelo dinamismo com que a experiência traz resultados nas economias locais - o que inaugura uma nova dinâmica produtiva, contribuindo significativamente para os altos índices de ocupação e de crescimento econômico do estado ${ }^{2}$ - e, principalmente, pelo padrão de reprodução e sociabilidade. Estes padrões são incorporados pelos trabalhadores envolvidos na confecção do jeans, que é a matéria-prima especial transformada pelos trabalhadores da cidade de Toritama ${ }^{3}$ - os quais se alojam, na sua maioria, em fabricos e facções ${ }^{4}$ para atender às encomendas dos empresários destes municípios.

Sob o ponto de vista do chamado dinamismo das economias, o modelo do APL almeja tornar-se a "novidade" no que tange à consolidação das propostas de desenvolvimento, tendo-se em conta sua vinculação com as reorientações da dinâmica capitalista para os países periféricos e a ampla difusão das experiências locais como alternativa de enfrentamento ao desemprego.

A pesquisa realizada junto ao Polo de Confecções do Agreste, que é um setor estratégico na economia pernambucana ${ }^{5}$, em especial no município de Toritama, levou a inferir que as formas pelas quais o trabalho se realiza no município caracterizam uma superexploração (MARINI, 2005), configurando-se em uma estratégia para a geração de excedentes na periferia do capitalismo. A superexploração combina aumento da intensidade do trabalho com prolongamento da jornada de trabalho e, ainda, com pagamento de baixos salários, através do assalariamento por peça. Desse modo, negando ao trabalhador a satisfação das condições mínimas necessárias à reposição de sua força de trabalho, impondo à grande parte desses trabaIhadores a condição de luta pela sobrevivência, cujo horizonte torna-se cada vez mais o consumo individual. O intuito é fazer com que a economia local gire e estimule a circulação, com a criação de um mercado local que consuma os bens produzidos pelo capital na região, em detrimento do acesso à esfera dos direitos sociais.

\footnotetext{
${ }^{2} \mathrm{O}$ estado de Pernambuco vem apresentando sucessivas e altas taxas de crescimento econômico. Segundo dados da Condepe/Fidem (2013), a economia estadual registrou, no segundo trimestre de 2013, um crescimento de 3,2\% na comparação com o segundo trimestre de 2012. Na comparação semestral, o PIB cresceu 2,9\% e, nos últimos 12 meses, $2,7 \%$.

${ }^{3}$ Toritama é o município que tem a menor extensão territorial do estado: $25.704 \mathrm{~km}^{2}$. Comporta uma população de 35.554 habitantes, distribuídos em uma densidade demográfica de 1383,21 hab/ $/ \mathrm{km}^{2}$.

${ }^{4}$ Os fabricos são pequenas unidades de produção em que ocorrem todas as etapas da pequena produção, as quais podem ser encomendas das empresas maiores ou ser direcionadas para a venda daqueles que produzem. Já as facções são marcadas pela produção de algumas partes da produção, ocorrendo, principalmente, através da terceirização da produção das empresas maiores ou de fabricos.

${ }^{5}$ Segundo o Sebrae (2012), o setor têxtil corresponde a $77 \%$ do PIB de Pernambuco e gera 100 mil postos de ocupação em dez municípios do Agreste. Atualmente, soma $70 \%$ das empresas pernambucanas, conforme os dados da Secretaria de Desenvolvimento Econômico do Estado. Os 12 mil empreendimentos registrados, em 2003, somaram cerca de 20 mil no ano de 2013. Destes, cerca de $80 \%$, são empreendimentos não formalizados.
} 


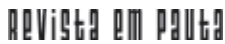

\} ARRANIOS PRODUTIVOS LOCAIS COMO ESTRATÉGIA NEODESENVOLVIMENTISTA - COSTA, F.; AMARAL, A. \} DOI: $10.12957 /$ rep.2015.21050

A informalidade apresentada nessa realidade, via terceirizações e subcontratações, insere-se na produção capitalista como forma de externalização da produção, na tentativa de redução dos custos, tanto com infraestrutura, quanto com os direitos trabalhistas. Neste sentido, a opção pela informalização constitui-se numa forma contemporânea de valorização do valor. Consequentemente, absorve-se a parcela sobrante de trabalhadores expulsos da esfera da produção, a qual se expande proporcionalmente ao crescimento do desemprego estrutural.

Chama atenção, nesta experiência, o destaque conferido à necessidade da formação de uma força de trabalho mais qualificada para ser incorporada aos processos da produção, tendo em vista o discurso que propaga o crescente investimento em tecnologias (informática, equipamentos computadorizados, máquinas de corte mais sofisticadas etc.). No entanto, essa modernização, restrita às empresas formalizadas e de grande e médio porte, coexiste com uma condição de precarização e superexploração do trabalho.

Nos argumentos da mídia, empresariado e lideranças políticas locais, comparece a afirmação de que a conjuntura atual marca uma nova etapa do capitalismo, caracterizada pela introdução de um conjunto de inovações tecnológicas que exigem novas modalidades de conhecimentos. Isto tem levado muitos autores a denominar este período como a "Era do Conhecimento" ${ }^{\prime \prime}$. Ao mesmo tempo, estimula-se o conhecimento tácito, o "saber fazer" como critério de inclusão dos trabalhadores nos processos produtivos.

Apesar de serem constatadas algumas formas mais modernas nas relações trabalho, as quais exigem uma maior qualificação por parte dos trabalhadores, o que predomina na experiência dos APLs são formas arcaicas de trabalho. Estas requerem do trabalhador um conhecimento mais simples, instrumental, e têm sido reproduzidas de maneira informal. O que se pode perceber é que se tem enfatizado o discurso das oportunidades que a constituição deste arranjo proporciona aos trabalhadores, com a promessa de inclusão produtiva através da plena ocupação no ramo das confecções ${ }^{7}$.

A nosso ver, esse discurso das oportunidades é um artifício com forte viés ideológico, já que possui um significativo potencial de impacto subjetivo sobre os trabalhadores, pois pretende convencê-los de que também estão inseridos no ciclo de desenvolvimento dos APLs, através da possibilidade de ocupação. Assim, fazendo-os crer que o projeto de desen-

\footnotetext{
${ }^{6} \mathrm{O}$ conhecimento e suas formas de disseminação estariam assumindo uma posição extremamente relevante na atualidade, visto serem elementos fundamentais na dinâmica da nova ordem mundial em conformação, já que são os principais condutores e possibilitadores das inovações requeridas pelo capital.

${ }^{7}$ Estudos recentes (IBGE, 2012) indicam que a participação das pessoas ocupadas no setor de confecções, no total da população em idade ativa, somente em Toritama, é de $61,4 \%$. Nos municípios que compõem a totalidade dos APLs, estes mesmos estudos revelam que $80 \%$ das unidades produtivas são informais e $20 \%$, formais.
} 
volvimento - crescimento econômico com melhorias sociais - pode ser partilhado por todos.

Nesse contexto, observa-se uma preocupação das instituições locais, tanto as de ensino quanto as associações e instituições de classe, em desenvolver ações de qualificação profissional dos trabalhadores. Tal preocupação pode ser demonstrada pela ampla oferta de cursos, capacitações, treinamentos, entre outras ações direcionadas ao Polo de Confecções. A análise dessas ações nos revela que elas são construtos sociais e políticos que operam na formação de um consenso por parte dos trabalhadores. Consenso este que deve ser edificado sob novas referências; não mais as estabelecidas pelo contrato social vigente, na sociedade burguesa, mas pela sua nova forma de operar na ordem social contemporânea: centrada no trabalho precarizado e desprotegido, sem qualquer vinculação à estrutura de proteção social e focada em um determinado perfil profissional, cujas características devem estar voltadas à capacidade de aquisição de competências individuais e de formação de empreendedores na região.

Por conseguinte, as ações empreendidas pelos agentes públicos e privados presentes nestes APLs influenciam e são influenciadas pelas demandas da dinâmica produtiva, a saber: criar ideias e valores ou, em outros termos, criar ideologias constitutivas de uma outra cultura do trabalho e um trabalhador de novo tipo.

Para alcançar os objetivos pretendidos na pesquisa, incialmente adotamos, como procedimentos metodológicos, um estudo exploratório da região, com o objetivo de conhecer a realidade local e o mapa das instituições que desenvolvem ações de qualificação profissional direcionadas especificamente ao ramo de confecções. Ademais, foram realizadas entrevistas semiestruturadas com os representantes dessas instituições.

Incluímos estabelecimentos de ensino públicos e privados, tais quais: Faculdade de Desenvolvimento e Integração Regional (Fadire), de Santa Cruz do Capibaribe; Serviço Nacional de Aprendizagem Industrial (Senai) de Santa Cruz do Capibaribe e de Caruaru; Serviço Brasileiro de Apoio às Micro e Pequenas Empresas (Sebrae) de Caruaru; Serviço Nacional de Aprendizagem Comercial (Senac) de Caruaru; Instituto de tecnologia de Pernambuco (Itep)/Centro Tecnológico da Moda de Caruaru; Universidade Federal de Pernambuco (UFPE) de Caruaru; e Universidade de Pernambuco (UPE) de Caruaru. Além destas, no universo da amostra de pesquisa, também foram incluídas instituições locais que atuam como articuladoras dessas ações ${ }^{8}$, uma lavanderia local de referência, bem como sete trabalhadores de facções, a fim de colher informações complementares.

A partir das informações obtidas nas entrevistas, procedemos à análise dos dados, momento no qual pôde-se identificar a ênfase evidenciada

\footnotetext{
${ }^{8}$ Associação Comercial e Industrial de Toritama (Acit); Associação das Facções e Aprontamentos de Toritama (Afat); Câmara de Dirigentes Lojistas (CDL) de Santa Cruz do Capibaribe.
} 


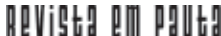

\} ARRANJOS PRODUTIVOS LOCAIS COMO ESTRATÉGIA NEODESENVOLVIMENTISTA - COSTA, F.; AMARAL, A. | DOI: $10.12957 /$ rep.2015.21050

nos discursos dos sujeitos entrevistados. Entendemos que esses discursos são uma fonte privilegiada para identificar os argumentos ideológicos e políticos que fundamentam as ações e suas mediações com a totalidade social.

Foram, ainda, realizadas pesquisas documentais e coleta de informações em fontes primárias e secundárias de dados, como o Instituto Brasileiro de Geografia e Estatística (IBGE), a Fundação Joaquim Nabuco (Fundaj), o Sebrae, a Rede de Pesquisa em Sistemas Produtivos e Inovativos Locais (Redesist), dentre outros.

Quanto à organização deste artigo, além desta seção de Introdução, constam ainda as Considerações finais e mais quatro partes. Na primeira, realizamos uma discussão dos APLs inseridos, na perspectiva do desenvolvimento regional, os quais são apresentados como importante estratégia de desenvolvimento das regiões mais periféricas do país. Na segunda, discorremos sobre a informalidade e a superexploração do trabalho na região. Na terceira, abordamos o tema da qualificação profissional, com enfoque para os argumentos em torno desta como formadora de capital humano e como proporcionadora de empregabilidade. Na última parte, empreendemos uma reflexão sobre a direção da qualificação profissional no contexto neodesenvolvimentista, com grande enfoque no estímulo ao empreendedorismo.

\section{O Arranjo Produtivo Local e a perspectiva do desenvolvimento regional}

A proposta de APLs se apresenta como partícipe da agenda pública em prol do desenvolvimento regional. Consiste em corrigir as desigualdades e heterogeneidades regionais históricas, na realidade brasileira, tendo como base o desenvolvimento do território.

A Região Nordeste se constituiu historicamente como periferia em relação ao sul do país. Dessa maneira, é imprescindível realizar as devidas interlocuções entre o que propõe a política pública dos APLs, que se relacionam com a difusão de novos conhecimentos e inovações tecnológicas, com a realidade específica onde se situa o universo de pesquisa, a fim de compreender as relações estabelecidas nesse processo e o lugar que tem sido ocupado pelas novas tecnologias e pelo conhecimento.

A proposta de desenvolvimento regional foi apresentada no Plano Nacional de Desenvolvimento Regional (PNDR) e elaborada pelo Ministério da Integração Nacional (MI), instituído em 2007. Tal proposta parte do suposto de que o processo de globalização atingiu de forma diferenciada os países em desenvolvimento e suas regiões, potencializando as desigualdades regionais históricas (ARAÚJO, 1999). Assim, compreende-se que, apesar de ter havido uma aceleração das configurações espaciais e da relação 


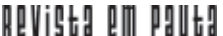

\} ARRANJOS PRODUTIVOS LOCAIS COMO ESTRATÉGIA NEODESENVOLVIMENTISTA - COSTA, F.; AMARAL, A. \}

DOI: $10.12957 /$ rep.2015.21050

espaço-tempo, algumas regiões ficaram fadadas à estagnação econômica, política e social. O texto do PNDR expressa essa questão:

Os países menos desenvolvidos são especialmente atingidos pelo ritmo desigual com que as empresas decretam a inclusão e a exclusão de regiões à dinâmica econômica global. Enquanto algumas áreas se tornam plataformas de operação das empresas, herdando atividades produtivas antes localizadas nos países centrais, outras são condenadas à estagnação econômica. Com isso, acentuam-se as desigualdades sociais e regionais e desencadeiam-se fluxos migratórios rumo às regiões dinâmicas, o que acirra conflitos sociais e intensifica as pressões sobre as políticas sociais e o planejamento. (BRASIL, 2007).

Para compreender a construção dessa e das demais políticas públicas que tinham por objetivo corrigir as distorções regionais, buscamos apoio na análise realizada por Oliveira (1977). Em tal análise, o planejamento surge como forma de o Estado intervir sobre as contradições entre a reprodução ampliada do capital nacional e regional, que aparecem como conflitos inter-regionais. Não sendo, portanto, marcados pela presença de um Estado mediador, mas de um Estado cooptado ou não pelas formas mais adiantadas da reprodução do capital, a fim de forçar uma homogeneização ou uma aparente integração nacional. Desse modo, compreendemos que o planejamento não se constitui como uma forma neutra da presença do Estado na resolução das disparidades regionais, mas sim como uma forma transmutada da luta de classes, tanto ao nível da reprodução global, quanto ao nível das diferenciações regionais.

O Brasil tem discutido mais intensamente a questão do desenvolvimento e da superação das desigualdades regionais desde a década de 1950, a partir do modelo do desenvolvimentismo, que buscava a superação do subdesenvolvimento por meio de pesados investimentos na industrialização. As políticas de desenvolvimento regional, por sua vez, balizavamse em conceitos de polos de crescimento e de atração de investimentos. Contudo, este modelo começou a dar claros sinais de esgotamento a partir da década de 1970; na América Latina, na década de 1980, momento em que a crise fiscal e a estagnação econômica afligiam o continente (UDERMAN, 2008).

Por consequência, a perspectiva do desenvolvimento regional perde relevância em um contexto mais geral de redução da intervenção pública no bojo de implementação do ideário neoliberal. Só na virada dos anos 1980/1990 é que se volta a discutir a necessidade da adoção de ações promotoras de modernização produtiva e integração competitiva que, além disso, também oferecessem enfrentamento ao quadro de crescentes disparidades regionais e de degradação das condições de vida da população.

Na conjuntura instalada no país, a partir do primeiro governo petista (2003-2010), efetivou-se a construção do PNDR, que defende a 


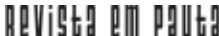

\} ARRANJOS PRODUTIVOS LOCAIS COMO ESTRATÉGIA NEODESENVOLVIMENTISTA - COSTA, F.; AMARAL, A. \} DOI: 10.12957/rep.2015.21050

possibilidade de o incentivo ao desenvolvimento não se limitar a regiões que já possuem produção flexível e inovações em sua base produtiva. De outra forma, esta política defende que a integração também ocorra em regiões periféricas. O plano cita, como exemplo, o caso dos APLs de Confecções do Agreste Pernambucano, que se encontra numa condição de atraso em relação ao desenvolvimento das forças produtivas que empregam as tecnologias mais modernas.

A proposta dos APLs se insere no ideário do desenvolvimento regional como estratégia de valorização da realidade local. Semelhante estratégia tem sido reconhecida por setores, como por exemplo o empresariado, pela sua capacidade de mobilizar a cooperação, a valorização das identidades locais e regionais e de incluir, de maneira participativa, amplos segmentos da sociedade.

Para além de serem pensadas como alternativas possíveis de superação das dificuldades econômicas e sociais, as pequenas e médias empresas são apreendidas como eixo fundamental e estratégico para o desenvolvimento econômico local. Urani, Cocco e Silva, (1999) reconhecem que, na realidade brasileira, as condições do mercado de trabalho, que excluem uma grande parte dos trabalhadores da formalidade e dificultam a possibilidade de construção de uma cultura política reivindicatória de melhores condições de trabalho, requerem um sério enfrentamento.

Neste contexto, mas numa perspectiva baseada nos conceitos de capital social e humano, sustentada num plano não econômico e não mercantil, começa a ser incorporada a ideia de que o Estado deve ser o principal mobilizador do desenvolvimento, com o fortalecimento de redes e habilidades locais pelos diversos organismos internacionais preocupados com o tema do desenvolvimento, como o Banco Mundial, o Banco Interamericano de Desenvolvimento (Bird) e a Organização das Nações Unidas (ONU).

Para Uderman (2008), essa perspectiva visa congregar elementos vinculados a bens públicos, redes sociais e cultura. Além disso, pretende encobrir os aspectos controversos, ressaltando a confluência de interesses em torno de determinadas intervenções. Teria como finalidade principal propor uma nova agenda de desenvolvimento, que não rompa com os veIhos paradigmas neoclássicos e não realize críticas substantivas ao modelo anteriormente defendido.

Desta feita, o modelo dos APLs emerge no seio da proposta de um neodesenvolvimentismo ou "novo desenvolvimentismo", que tem sido apontado como uma "Terceira Via":

uma estratégia de desenvolvimento alternativo aos modelos em vigência na América do Sul, tanto ao 'populismo burocrático', representado por setores arcaicos da esquerda e partidários do socialismo quanto à ortodoxia convencional, representada por elites rentistas e defensores do neoliberalismo [...] cujo principal objetivo é delinear 
um projeto nacional de crescimento econômico combinado com uma melhora substancial nos padrões distributivos do país [...] um determinado padrão de intervenção do Estado na economia e na 'questão social'” (CASTELO apud MOTA; AMARAL; PERUZZO, 2010, p. 40).

Dentre outras medidas, o neodesenvolvimentismo tem posto em prática a adoção de políticas de exceção, marcadas pela crescente substituição do direito ao trabalho protegido e amparadas na agenda neoliberal, sob a ideologia do autoemprego, do empreendedorismo, dos negócios próprios, da acumulação de capital social e da sustentabilidade. Do mesmo modo, são mediadas pelo discurso das oportunidades, da autonomia e da liberdade de escolha individual. Neste sentido, os APLs são apontados como capazes de dinamizar as economias locais. Esses arranjos disseminam ideias de que são promotores de maior rapidez da produção e da circulação e, por consequência, potencializadores do consumo.

Neste contexto, tem havido uma maior preocupação por parte dos organismos internacionais, principalmente do Banco Mundial, em estabelecer como condicionantes para o investimento, nos países em desenvolvimento, a valorização dos aspectos sociais e culturais como uma forma de conferir um "rosto humano" ao capital. Essas ideias amparam-se em pensamentos como o de Fukuyama (apud D'ARAÚJO, 2003), que afirma a importância dos aspectos morais, mobilizadores do capital social, como indispensáveis ao desenvolvimento das organizações. A ideia de alavancar o capital social aparece, portanto, com força nas propostas dos APLs, como forma de garantir o desenvolvimento.

Além dos investimentos das agências multilaterais de desenvolvimento (Bird, BID, Banco Mundial), a proposta dos APLs recebe incentivos de diversos agentes governamentais e não governamentais (Sebrae, Senai, Senac) nacionais, bem como de centros de formação, como a Redesist. Estes têm formulado seus próprios conceitos a respeito dos APLs, amparados em arcabouços ideológicos que enaltecem essa modalidade de experiência produtiva, sem realizar, a nosso ver, as devidas mediações com a nossa realidade.

Cabem, pois, algumas ponderações sobre a discussão do desenvolvimento econômico regional em uma realidade na qual a industrialização se deu tardiamente em relação às regiões mais desenvolvidas do país. Nesse sentido, compete, aqui, a discussão sobre a forma como esse processo de desigualdade regional se constituiu historicamente. Vale questionar, também, o que significa esse processo ter sido marcado pela ausência de incentivos efetivos ao desenvolvimento nessa região, excetuando-se algumas experiências pontuais, que não deram, ainda, conta de superar as desigualdades existentes.

$\mathrm{Na}$ realidade do Nordeste, constata-se a presença de um discurso que compreende a proposta dos APLs, a exemplo do Polo de Confecções do Agreste, como modelo econômico de desenvolvimento. No entanto, 
nosso posicionamento é o de que esse desenvolvimento tem se realizado à custa da utilização de uma força de trabalho barata e desqualificada, submetida a um intenso processo de superexploração.

Mais recentemente, conectado ao movimento mais geral da economia nacional, a região tem apresentado novos níveis de crescimento econômico, assentados no processo de liberalização da economia nacional e marcados pela ausência de uma política de desenvolvimento industrial no Sul e no Sudeste, momento propício aos maiores estados do Nordeste (Bahia, Ceará e Pernambuco). Estes iniciaram uma estratégia de concessão de incentivos, a chamada "guerra fiscal", política de atração de indústrias por meio da renúncia de tributos, que seria adotada pelos demais estados posteriormente (CARVALHO, 2008). Assim, várias indústrias, antes localizadas no eixo Sul-Sudeste, migraram dos espaços saturados a fim de baixar os custos de produção em outras regiões, sendo a Região Nordeste um destino privilegiado. Mais recentemente, a economia do Nordeste vem se projetando pelo fortalecimento e/ou surgimento de áreas com estruturas modernas que comandam a dinâmica regional, dentre as quais se insere o polo estudado.

Os dados sobre o crescimento da região têm sido expressivos: o PIB tem apresentado um crescimento maior que a média nacional, que se expressa pelo crescimento de 3,7\%, em 2014, sobre 2013, enquanto que o Brasil cresceu apenas $0,1 \%$. No entanto, segundo dados do IBGE (2012), o PIB per capita, no Nordeste, permanece baixo em relação à média nacional, que em 2014 foi de $\mathrm{R} \$ 22,645$ por pessoa, enquanto que na Região Nordeste ficou em R\$ 11.044 por pessoa. O índice de Gini ${ }^{9}$ da região demonstra a forte desigualdade na distribuição da renda, sendo a maior do país em 2013, ficando em 0,523 - enquanto que a do país foi de 0,498. Ou seja, a Região Nordeste se constitui como a mais desigual.

Segundo dados do IBGE (2012), a taxa de analfabetismo também segue elevada na região: entre a população acima de 15 anos é de $9,6 \%$ no país, chegando a $28 \%$ nos municípios da Região Nordeste. Apesar dos crescentes investimentos na região, bem como com o acesso das famílias à renda, principalmente através do aumento progressivo no valor do salário mínimo e da inserção em programas de transferência de renda, a exemplo do Programa Bolsa Família ${ }^{10}$, os indicadores sociais demonstram como esse crescimento dos últimos tempos não deram conta de modificar os traços mais fortes da herança histórica de desigualdades na região.

\footnotetext{
${ }_{9}^{9}$ Padrão internacional para medição da distribuição de renda.

${ }^{10}$ De acordo com dados divulgados pelo Instituto de Pesquisa Econômica Aplicada (Ipea), a Região Nordeste recebeu $51,1 \%$ dos benefícios do Programa Bolsa Família distribuídos em dezembro de 2011, sendo que essa região corresponde apenas a $28 \%$ da população nacional. Isto demonstra que a região tem a maior concentração de pobreza do país. Pernambuco é o $4^{\circ}$ estado a receber mais recursos do programa nacionalmente.
} 
Embora a região receba crescentes incentivos do governo federal, isso não tem se traduzido em investimentos em políticas públicas permanentes que provoquem reais alterações no quadro de desigualdade social, ainda predominante. A pretensão das políticas de transferência de renda se esgota na promoção de acesso dos trabalhadores ao consumo, já que visam apenas fazer girar a economia local.

Particularmente em relação ao APL de Confecções do Agreste Pernambucano, a Nota Técnica no 02 da Redesist (2010) alerta que o grande contingente de unidades produtivas informais não tem acesso às inovações nem aos programas de capacitação de força de trabalho, atualização tecnológica, capacitação gerencial e financiamentos públicos. Essas unidades

São caracterizadas por copiarem o design dos produtos das empresas maiores, por contarem com um quadro de pessoal ocupado de baixa escolaridade e influenciarem os rendimentos dos estabelecimentos formalizados, devido a seus custos menores (ANDRADE apud REDESIST, 2010, p. 41).

Ainda de acordo com o documento da Redesist, o alto grau de informalidade das empresas consiste no maior problema dos APLs, já que são muitas confecções que ficam à margem ou ganham muito pouco dos benefícios gerados pela estrutura do arranjo, principalmente, no que diz respeito: (i) ao aprendizado e inovação das empresas; (ii) à qualificação da mão de obra; (iii) ao acesso ao crédito; (iv) à submissão a formas precárias de trabalho.

Assim, pudemos constatar que as políticas públicas voltadas ao Polo de Confecções de Pernambuco não têm possibilitado alterações reais na qualidade de vida e de trabalho da população ali inserida, e nem de acesso aos direitos sociais. O que se pode inferir da ação do Estado é que há uma tentativa de legitimar formas precárias de trabalho, principalmente via informalidade, as quais, historicamente, eram tidas como atrasadas, não se observando a existência de uma legislação que garanta os direitos trabalhistas.

\section{A informalidade e a superexploração do trabalho na região}

A forte presença do trabalho informal na região se apresenta como útil ao capital e não como algo externo ou independente dele. Esta modalidade tem sido utilizada por diferentes empresas capitalistas sob a forma de trabalho assalariado por peça. Ademais, a pequena produção só é possível porque há uma permissão, por parte do capital, para que essas pequenas empresas ocupem alguns espaços, que podem ser a qualquer momento (re)assumidos pelo grande capital. Tavares (2004, p. 29) afirma que 
muitos trabalhadores são explorados sob formas diminutivas, como expressam as denominações usuais: 'pequeno capital', 'pequena produção', 'pequena empresa'. Organizados em cooperativas, associações, empresas e até familiarmente, os trabalhadores disponibilizam a sua força de trabalho sem vínculo empregatício para o núcleo capitalista, demonstrando a concretude da relação entre trabalho informal e capital.

O fato de a relação se dar informalmente não impede que o trabalhador deixe de ser impotente nesse processo, visto que o trabalho é executado mediante planejamento externo pela empresa que o contrata, que planeja e comanda diretamente esse trabalho, como parte de um trabalho coletivo. "Assim, apesar de a compra da força de trabalho ser mascarada pelas formas já abordadas, o momento da produção é determinante da funcionalidade do trabalho informal ao capital" (TAYAARES, 2004, p. 31).

Tavares (2010, p. 31) afirma que há um novo modelo em voga, conformado por um núcleo, uma espécie de empresa-mãe. Este é circundado por empresas pequenas, que funcionam como os antigos departamentos da empresa fordista: "Esse arranjo explica o fenômeno da terceirização, mecanismo que se propaga e que se traduz em diferentes formas de organização da produção, propiciando novas modalidades de exploração, algumas delas sob a ilusão do trabalho autônomo". No ciclo produtivo de Toritama, muitas empresas terceirizam parte de sua produção para trabalhadores em domicílio ou pequenas facções, fazendo o pagamento através do salário por peça a preços muito baixos. Isto acaba obrigando os trabalhadores a intensificarem a jornada de trabalho, muitas vezes trabalhando durante horas a fio e envolvendo todos os membros da família, inclusive crianças e idosos, para darem conta da produção.

A base do trabalho doméstico é, segundo Marx (1980), o salário por peça. Sobre este salário, Tavares (2004) afirma que ele se ajusta muito bem ao atual momento de reestruturação produtiva, em que o Estado se torna ainda mais permissivo do ponto de vista de uma maior exploração do trabalhador e extração de mais-valia. Ora, Marx (1980) afirma que esta modalidade de trabalho dá a falsa impressão de que não há a determinação do fator tempo na produção. Além disso, que o produto, valor de uso, não resulta da força de trabalho, do trabalho vivo, mas aparece como a materialização do trabalho no produto. $\mathrm{O}$ autor sustenta que o salário por peça corresponde ao tempo despendido pelo trabalhador pelo número de peças que este produziu, ou seja, o tempo continua sendo determinante para estabelecimento do valor diário da força de trabalho, sendo o salário por peça "apenas uma forma modificada do salário por tempo" (MARX, 1980, p. 639).

Além da utilização da modalidade de salário por peça, observase, no APL de Confecções do Agreste, em especial no município de Toritama, 


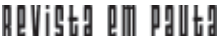

\} ARRANJOS PRODUTIVOS LOCAIS COMO ESTRATÉGIA NEODESENVOLVIMENTISTA - COSTA, F.; AMARAL, A. \}

DOI: $10.12957 /$ rep.2015.21050

a ampliação da jornada de trabalho e a intensificação da utilização da força de trabalho. Grande parte dos trabalhadores é terceirizada e trabalha no próprio domicílio ou em pequenas facções, que muitas vezes não possuem as condições mínimas de trabalho e de salubridade.

Concordamos com Tavares (2008) quando este afirma que a transferência da produção para as residências dos trabalhadores, além de se configurar numa invasão ao ambiente familiar do trabalhador, proporciona a prática do trabalho não pago, que incorpora toda a família, incluindo crianças e idosos, não deixando lugar para as outras dimensões humanas da vida do trabalhador e de sua família. É exatamente isso que observamos na realidade pesquisada, em que os baixos preços pagos pela produção pressionam esses trabalhadores e sua família a trabalharem por longas jornadas, intensificando o processo de trabalho para darem conta de uma produção que lhes garanta o mínimo necessário para sua sobrevivência. Dessa forma, não lhes resta espaço para a satisfação de outras necessidades, como o acesso ao lazer, por exemplo.

Esse processo encontra suporte na categoria da superexploração do trabalho ${ }^{11}$. Marini (2005) aborda a superexploração do trabalho em $A$ dialética da dependência ${ }^{12}$, explicando os condicionantes da reprodução ampliada do capital no continente latino-americano a partir da superexploração do trabalho. O autor realizou uma importante contribuição para pensarmos as relações que se estabelecem entre as economias do centro e da periférica. No seu estudo sobre a relação dialética e complementar entre desenvolvimento e subdesenvolvimento, contraria as visões vigentes de que o subdesenvolvimento, presente nas economias periféricas, seria passível de correção. Com base nesse argumento, entendia-se o subdesenvolvimento como uma fase anterior ao desenvolvimento, numa perspectiva etapista da história. Marini (2005) asseverava, no entanto, haver uma relação dialética e complementar entre os dois termos, sendo o subdesenvolvimento resultado do que determina o desenvolvimento, na lógica da acumulação capitalista (CARCANHOLO, 2005).

O estudioso apresenta, como condicionantes históricos da dependência, as perdas sofridas nos termos da troca entre a periferia e o centro, a remessa dos excedentes criados na periferia para os países centrais e a instabilidade do mercado internacional, que provoca o aumento das taxas de juros. Dessa forma, uma grande quantidade de mais-valia extra é transferida para o centro. O capital externo presente nos países periféricos reparte os lucros e dividendos e os remete para os países centrais. A transferência de valor ainda se dá através da dependência tecnológica (royalties).

\footnotetext{
${ }^{11}$ Elaborada por Ruy Mauro Marini, essa categoria corresponde a um movimento de mediação com a teoria marxiana, na qual o pensador aborda a concretude da dependência latino-americana e da exploração do trabalho no continente, guardando as particularidades do nosso contexto histórico.

${ }^{12}$ A obra original foi publicada em 1973.
} 
Por consequência, a maneira encontrada pela economia dependente é aumentar a produção de excedentes, o que se realiza através da superexploração da força de trabalho, expressa, atualmente, no arrocho salarial, na extensão da jornada de trabalho e no aumento da sua intensidade. Assim, a superexploração do trabalho tem garantido a dinâmica capitalista na periferia (CARCANHOLO, 2005).

A exploração do trabalho se dá, nesta conjuntura histórica, através do aumento da intensidade e da jornada de trabalho, bem como da redução do consumo do operário além do seu limite normal. Neste há, nos termos de Marx, a transformação do fundo de consumo do operário em fundo de acumulação do capital, havendo o aumento do tempo de trabalho excedente (MARINI, 2005). Esse quadro foi responsável pela forma como tem se realizado a economia industrial latino-americana na atualidade, pois seu ingresso na etapa da industrialização se deu a partir das bases criadas pela economia de exportação, com efeitos decisivos sobre a exploração do trabalho. Assim, continua a haver uma atividade subordinada à produção e à exportação de bens primários, que permanecem constituindo-se no centro vital do processo de acumulação; uma superexploração dos trabaIhadores como forma de equilibrar os níveis de lucratividade com o contexto externo.

Nos mecanismos supramencionados, a característica essencial consiste na negação das condições necessárias ao trabalhador para repor sua força de trabalho. Significa, pois, que o trabalho passa a ser remunerado abaixo do seu valor, o que corresponde a uma superexploração do trabalho.

Há um aumento da intensidade e da jornada de trabalho, o que na realidade acaba diminuindo o rendimento dos trabalhadores e aumentando a extração da mais-valia, ainda que, aparentemente, eles estejam acessando uma renda. Como as suas necessidades não têm sido atendidas satisfatoriamente através da proteção social, esses trabalhadores precisam buscar, em geral individualmente, pela via do consumo, o atendimento mercantil às suas necessidades básicas.

Compreendemos, pois, que as condições estruturais da dependência se asseveram na realidade estudada. Além disso, as novas condições de consumo determinam um processo ainda maior de alienação por parte do trabalhador, que entende que sua cidadania se realiza na esfera do consumo. Este vem a fortalecer a conformação do "cidadão consumidor", nos termos de Mota (2000).

\section{Qualificação profissional: do capital humano à empregabilidade}

No período histórico em que vigorou a organização taylorista/ fordista de produção, o papel atribuído à qualificação profissional se re- 


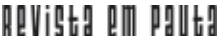

\} ARRANJOS PRODUTIVOS LOCAIS COMO ESTRATÉGIA NEODESENVOLVIMENTISTA - COSTA, F.; AMARAL, A. \}

DOI: $10.12957 /$ rep.2015.21050

lacionava às possibilidades de um maior incremento do excedente. Neste quadro, a educação foi entendida como formadora de capital humano, como um fator fomentador da capacidade produtiva, através de um acréscimo de instrução, treinamento e educação ao trabalhador.

A teoria do capital humano é uma esfera particular da teoria do desenvolvimento, marcada pelo contexto em que foi produzida, uma das expressões ideológicas dominantes desse período. A teoria do desenvolvimento, geral e abrangente, pelas suas características e pela problemática abordada, é muito mais uma teoria da modernização do que uma teoria explicativa do desenvolvimento capitalista, isto é, das bases materiais e das condições sociais em que assenta o processo de produção e reprodução das formações sociais capitalistas. (GRYBOWSKI et al., apud FRIGOTTO, 1996, p. 40).

Desta forma, a educação e a formação de capital humano eram vistas como rentáveis, posto que possibilitariam a ampliação do volume de conhecimentos e habilidades adquiridos, de modo a potencializar a capacidade produtiva do trabalho e, consequentemente, a acumulação de capital.

No Brasil, esta perspectiva se coadunou às discussões desenvolvimentistas e da equidade social, no cenário do chamado milagre econômico. O incentivo ao capital humano era apresentado como meio de dissolução das desigualdades sociais, pois os defensores dessa ideia afirmavam que, por meio do investimento em educação, os países em desenvolvimento poderiam alcançar padrões de desenvolvimento, tendo como modelo os países centrais, onde vigoravam o estado de bem-estar e o pleno emprego. Ideia esta que ganhou bastante força na América Latina mediante incentivo dos organismos internacionais (BID, Bird, OIT, Unesco, FMI, Cepal, entre outros). Como afirmado por Frigotto (1995, p. 41-42):

É na crença nesta mágica solução, ao largo das relações de poder na sociedade, que um dos mais ilustres representantes da escola econômica neoclássica no Brasil, Mário H. Simonsen, no final da década de 60 e início de 70, pregava ao mundo que o Brasil tinha encontrado seu caminho para o desenvolvimento e eliminação das desigualdades, não pelo incentivo ao conflito de classes, mas pela equalização do acesso à escola e pelo alto investimento em educação (Simonsen, 1969). (Grifo nossos).

A discussão sobre o investimento em "capital humano" passou a se constituir num importante fator que poderia solucionar o enigma do subdesenvolvimento e das desigualdades internacionais, regionais e individuais. A teoria do capital humano provocou um intenso debate, particularmente nas décadas de 1960 e 1970; ao mesmo tempo, teve um amplo uso político e ideológico na definição de macropolíticas educacionais orientadas pelos organismos internacionais e regionais. 


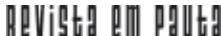

\} ARRANIOS PRODUTIVOS LOCAIS COMO ESTRATÉGIA NEODESENVOLVIMENTISTA - COSTA, F.; AMARAL, A. DOI: $10.12957 /$ rep.2015.21050

No contexto da crise capitalista de finais dos anos 1970 até os dias atuais, a teoria do capital humano se reatualiza: da promessa do pleno emprego passa-se à promessa da empregabilidade. Nos países centrais, bem como na periferia do capitalismo, o sistema educacional começa a preparar o trabalhador para o desemprego estrutural e todas as implicações que ele acarreta.

A ideia aqui subjacente é a de que os que perdem seus empregos ou não conseguem se inserir no mercado de trabalho estão nessa condição por incompetência ou por não fazerem escolhas acertadas. Noutros termos: "as vítimas do sistema excludente viram os algozes de si mesmos" (FRIGOTTO, 1995, p. 46). Desta feita, as concepções de educação básica e de formação profissional, como estão definidas na atualidade, desvinculamse de um projeto econômico, político e cultural que apresente uma clara proposta de geração de emprego e renda, ou mesmo de qualquer possibilidade de prática desalienante.

A empregabilidade se constitui, portanto, em um conceito ideológico, que desconsidera as relações sociais, políticas e econômicas determinantes do desemprego. Essa situação, de fato, contribui para retirar do Estado e do sistema capitalista a função de garantir condições mínimas para a reprodução dos trabalhadores. Portanto, de colocar sobre estes a responsabilidade de estabelecer estratégias que garantam sua inserção no mercado de trabalho. De igual forma, o conceito de competência também faz parte desta estratégia, pois institui os condicionantes para que a empregabilidade possa se realizar. Com efeito, são as competências que interessam ao patrão que tornarão o trabalhador empregável ou não.

No caso do Polo de Confecções do Agreste pode-se identificar uma forte articulação por parte do empresariado local - principalmente através de suas associações - no sentido de mobilizar ações de qualificação profissional. Do ponto de vista dos trabalhadores, com exceção de incipientes alternativas, o que se pode observar, de modo geral, é a falta de mobilização política e a ausência de ações de qualificação profissional nas quais os trabalhadores sejam sujeitos efetivos.

Frente a este processo, o empresariado local tem assumido um papel dirigente e, para manter esse controle, lança mão de instituições parceiras que defendem os seus interesses. Além de assegurar uma base material para a produção e reprodução do sistema, o capital necessita formar uma determinada cultura do trabalho e disseminá-la, por meio dos novos padrões de gestão da produção ou por meio de seus aparelhos privados de hegemonia.

É assim que o Sistema $\mathrm{S}^{13}$ tem sido historicamente uma base de apoio para treinar a força de trabalho nos moldes dos interesses empresariais. Segundo Amaral (2005, p. 158):

\footnotetext{
${ }^{13}$ O Sistema S é formado, atualmente, por: Pequenos Negócios: Sebrae. Indústria: Sesi; Senai; Sesc; Senac; Campo: Serviço Nacional de Aprendizagem Rural (Senar). Transportes: Serviço Social de Transporte (Sest); Serviço Nacional de Aprendizagem do Transporte (Senat).
} 
A formação profissional voltada aos interesses do mercado não é algo novo no Brasil. Desde a década de 40 do século passado que o empresariado intervém no processo de formação da força de trabalho, mediante a criação de organismos específicos no sentido de se formar trabalhadores para o processo crescente de industrialização. Estes organismos podem ser considerados 'aparelhos privados de hegemonia', na concepção gramsciana, posto que pretendem socializar, na sociedade, sua visão de mundo, seus valores, suas propostas como sendo ideias dominantes.

Seguindo esse propósito, as instituições do Sistema S, principalmente o Senai e o Sesi, têm um importante papel como formadores de um padrão de trabalhador compatível com as necessidades do mercado, privilegiando em seus cursos conteúdos de caráter disciplinador e instrumentais prático-operativos voltados ao "saber fazer". Já o Sebrae tem tido uma forte atuação no estímulo ao empreendedorismo para o trabalhador, e contribui para formar uma nova cultura do trabalho, com ênfase no trabalho desprotegido.

A própria ausência do Estado, ou sua frágil intervenção, favorece o direcionamento privado das ações de qualificação profissional neste polo. Vale ressaltar que essa ausência se dá apenas do ponto de vista da execução de políticas públicas voltadas às garantias dos direitos sociais dos trabaIhadores. Isto porque tem sido decisiva a sua intervenção como agente de repasse de recursos públicos, para que o setor privado direcione as ações de qualificação profissional através das iniciativas para as quais são direcionados projetos de execução das instituições privadas, por exemplo.

Nessa direção, a qualificação profissional tem sido um campo propício ao desenvolvimento da tentativa de construção da hegemonia burguesa. Cabe ressaltar que é, pois, no movimento dialético da sociedade que se constrói a hegemonia de uma classe sobre a outra, da subordinação e coordenação dos subalternos pelos dominantes. Coutinho (2003, p. 128) afirma que: "no âmbito e através da sociedade civil, as classes buscam exercer sua hegemonia, ou seja, buscam ganhar aliados para sua posição mediante a direção política e o consenso". Para Gramsci (1978), a hegemonia está relacionada com a capacidade de direção e de estabelecimento de consenso em torno de determinado projeto; não opera apenas na estrutura econômica e organização política da sociedade, mas também sobre o modo de pensar e sobre suas orientações ideológicas. Uma classe é hegemônica até o momento em que consegue manter sua dominação sobre a outra, possuindo a capacidade de unificar, através da ideologia, um grupo heterogêneo, impedindo a existência de uma fratura que provoque uma crise na ideologia dominante e sua consequente recusa.

Assim, para criar consensos, por parte dos trabalhadores, em relação aos interesses capitalistas, a qualificação profissional difunde uma nova cultura do trabalho através de uma propagação positiva das novas relações 


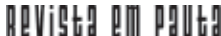

\} ARRANJOS PRODUTIVOS LOCAIS COMO ESTRATÉGIA NEODESENVOLVIMENTISTA - COSTA, F.; AMARAL, A. \} DOI: $10.12957 /$ rep.2015.21050

de trabalho, que têm se mostrado extremamente precárias. Nesta direção, Mészáros (2008, p. 43-44) afirma:

Aqui a questão crucial, sob o domínio do capital é assegurar que cada indivíduo adote como suas próprias as metas de reprodução objetivamente possíveis do sistema. Em outras palavras, no sentido verdadeiramente amplo do termo educação, trata-se de uma questão de 'internalização' pelos indivíduos - [...] da legitimidade da posição que Ihes foi atribuída na hierarquia social, juntamente com suas expectativas 'adequadas' e as formas de conduta 'certas sendo protagonizada, no âmbito da educação profissional, pelos agentes privados que dirigem esse processo'. (Grifo no original).

Observa-se, pois, um esforço por parte do empresariado em gerenciar as instituições de ensino, ao mesmo tempo em que tenta preservar o caráter privado de seus espaços pedagógicos, à medida que constrói uma estrutura organizacional para gerenciar essas ações. Para isso, ampara-se no argumento de que uma maior quantidade de trabalhadores escolarizados levaria a um maior desenvolvimento econômico do país, e que o acesso à educação oferece, concretamente, a possibilidade de mobilidade social.

Este mesmo empresariado continua delineando e atualizando seu projeto para a educação profissional, imprimindo-lhe um caráter mercantil, através de conceitos como competência, empregabilidade, estímulo ao empreendedorismo e à transformação dos trabalhadores em pequenos empresários, sob a ideologia da autonomia e da liberdade. Esse projeto visa formar uma pretensa massa de pequenos empreendedores que possam se inserir na nova dinâmica produtiva, assentada na lógica da fábrica enxuta, com a externalização de inúmeras etapas da produção, a exemplo da proposta dos APLs.

Nesta direção, ora o empresariado defende uma autonomia em relação ao Estado, ora o reivindica como instrumento ágil, enxuto, desengessado. Neste caso, o afastamento do Estado da economia torna-se apenas uma aparência necessária pois, apesar das críticas realizadas contra ele, continua reclamando uma atuação efetiva em processos que the sejam favoráveis, como as reformas que vêm sendo realizadas e que representam uma forte ofensiva contra os direitos sociais conquistados historicamente.

\section{Qual a direção da qualificação profissional no contexto neodesenvolvimentista?}

No processo de produção de mercadorias, no Polo de Confecções em tela, é predominante o uso de trabalho simples, informal, realizado nos domicílios dos próprios trabalhadores. Isso significa que, em larga medida, não há necessidade de mobilização de conhecimentos mais complexos por partes deles. Ao mesmo tempo, podemos observar que, nas empresas 


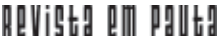

\} ARRANJOS PRODUTIVOS LOCAIS COMO ESTRATÉGIA NEODESENVOLVIMENTISTA - COSTA, F.; AMARAL, A. \}

DOI: $10.12957 /$ rep.2015.21050

formalizadas, onde são realizados os processos mais sofisticados da produção, as ações e as exigências de qualificação profissional são maiores.

Neves e Pronko (2008), amparadas na teoria marxiana, informam-nos sobre a diferenciação da formação voltada ao trabalho simples e ao trabalho complexo. Para elas, o trabalho simples se caracteriza por sua natureza indiferenciada, ou seja, dispêndio de força de trabalho que os homens comuns, mesmo sem educação especial, possuem em seus organismos (MARX apud NEVES; PRONKO, 2008, p.29). Por sua vez, o trabalho complexo se caracteriza por ser de natureza especializada, requerendo, por isso, maior dispêndio de tempo de formação daquele que irá realizálo.

Tendo isso em vista, o que percebemos foi que há heterogeneidade, numa mesma região, tanto nas relações de trabalho quanto nas formas como se realiza a produção. Parte dessa produção ocorre no interior das grandes empresas, enquanto outra parte acontece externamente aos domicílios. A constatação desse paradoxo irá, entretanto, demandar conhecimentos diferenciados por parte dos trabalhadores, a depender da forma de inserção na cadeia produtiva.

As exigências do capital para a formação voltada ao trabalho simples e complexo sofrem alterações periódicas de conteúdo e preparação para o trabalho. Isto acontece uma vez que a produção material e simbólica se racionaliza pelo emprego diretamente produtivo da ciência para a reprodução ampliada do capital, tendo o trabalhador coletivo que se adaptar aos valores e práticas da cultura urbano-industrial.

Na configuração capitalista contemporânea, o que tem sido enfatizado é uma imposição pela ampliação quantitativa dos anos de escolaridade básica, além de uma nova organização curricular. Esta é voltada para o desenvolvimento de capacidades técnicas e de uma nova sociabilidade dos trabalhadores para a reprodução ampliada do capital e, também, para a obtenção do seu consentimento ativo frente às atuais relações de dominação e exploração burguesas. Do ponto de vista do capital, a formação para o trabalho simples serve para o aumento da produtividade do trabalho, bem como para a formação de um homem coletivo adaptado às novas exigências de exploração e dominação capitalistas.

Assim, identificamos um forte componente ídeo-político nas ações de qualificação profissional desenvolvidas na realidade estudada. Ações que têm sido predominantemente direcionadas por instituições privadas e possuem forte articulação entre si, atuando na conformação de consensos em torno de um projeto classista. Neste projeto, busca-se incutir no trabalhador a aceitação das suas condições precárias de trabalho como algo natural e positivo por representar uma pseudoliberdade, sob a ideologia do empreendedorismo.

Tais considerações nos levam a concluir que há, nestes APLs, e especialmente no do Polo de Toritama, um projeto de qualificação que 


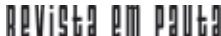

\} ARRANIOS PRODUTIVOS LOCAIS COMO ESTRATÉGIA NEODESENVOLVIMENTISTA - COSTA, F.; AMARAL, A. DOI: 10.12957/rep.2015.21050

utiliza recursos tecnológicos mais inovadores para minimamente racionalizar a produção mais sistemática. Porém, esta dinâmica apresenta um limite que produz um desenvolvimento desigual e combinado neste arranjo. Permeia, também, o processo de difusão da educação, pois o trabalho desenvolvido pela grande massa dos trabalhadores não demanda uma qualificação profissional mais ampla, integral e complexa.

O trabalho domiciliar envolve todos os membros da família, que se submetem a intensas jornadas de trabalho. Parece ao trabalhador um ambiente de plenas liberdade e autonomia, pela ausência da figura do patrão. No entanto, sustentamos que esta modalidade de trabalho contribui para uma maior exploração do trabalhador e sua família, por não permitir a distinção entre o tempo de vida e o tempo de trabalho.

Esta é uma das principais razões pelas quais a grande massa dos trabalhadores não acessa, ou pouco acessa, a qualificação profissional, além de não participar do processo de escolha do modelo educacional proposto para a realidade que vivenciam. Há uma distinção entre a qualificação voltada à grande massa, que consiste nas iniciativas mais informais, e aquela voltada aos trabalhadores vinculados às empresas, que são os sujeitos da qualificação profissional no polo.

Podemos afirmar que a ideologia do empreendedorismo tem sido o principal fundamento ídeo-político disseminado neste arranjo. Isso se dá, dentre outros mecanismos, através da qualificação profissional, que tem um papel estratégico como conformadora de uma nova cultura do trabalho, sustentada em uma inserção produtiva precária e flexível. Este modelo está referenciado em uma perspectiva de desenvolvimento local, cujos princípios e diretrizes cabem perfeitamente nos argumentos que invocam a estratégia neodesenvolvimentista como possibilidade de gerar crescimento econômico e desenvolvimento social na região.

As ações de qualificação profissional consistem, pois, em uma estratégia privilegiada de disseminação do ideário burguês em torno da apologia ao trabalho precário, sob a ideologia do empreendedorismo. Trabalho precário que se realiza com a desregulamentação dos direitos sociais e trabalhistas e a precarização das condições de trabalho, assumindo formatos de terceirização, informalidade e trabalho domiciliar, submetendo os trabalhadores às mais vis condições de trabalho e superexploração em prol da produtividade.

Essas condições são intensificadas em uma realidade como a da Região Nordeste, em particular no Agreste Pernambucano, que tem características históricas de industrialização tardia e precárias condições de assalariamento, com tradição nas atividades rurais. Neste cenário, a opção pelas alternativas urbanas, relacionadas às iniciativas empreendedoras, torna-se um atrativo para esses trabalhadores oriundos das atividades laborativas rurais.

A formação de um perfil de trabalhador empreendedor para atuar no polo pesquisado foi o elemento mais enfatizado nos discursos dos sujeitos 
entrevistados. Consiste, pois, no enfoque principal presente na conformação da nova cultura do trabalho, constituindo-se no principal fundamento ideológico e político das ações de educação profissional empreendidas na localidade. O empreendedorismo é apresentado como característica essencial aos trabalhadores locais, sempre defendido como alternativa de trabalho e renda para os mesmos. A ideia é a de que os trabalhadores que desenvolvem tal característica podem, caso não consigam uma ocupação formal, se inserir no mercado de trabalho, fomentando o próprio negócio.

A utilização desse conceito está fortemente atrelada ao de empregabilidade, tornando-se atributo essencial que deve compor o novo perfil do trabalhador, diante de um mercado cada vez mais reduzido e com poucas possibilidades de inserção, a fim de tornar esse trabalhador passível de inclusão na dinâmica produtiva.

A nosso ver, a questão do estímulo ao empreendedorismo, apesar de possuir mediações com a questão cultural disseminada historicamente na região, possui determinantes macroestruturais, que o fazem parecer, para grande parcela da população local, como a única alternativa de ocupação e obtenção de renda. Semelhante ideia tem sido legitimada pelos sujeitos envolvidos com a educação na localidade e pelo próprio Estado, que tem cada vez mais investido em políticas públicas de geração de ocupação e de renda, em detrimento da criação de empregos estáveis e socialmente protegidos.

Esse processo sofre inflexões da reestruturação produtiva do capital e, principalmente, da posição subalterna que os países periféricos e de industrialização tardia têm ocupado na divisão internacional do trabalho. Consequentemente, ocorre o agravamento do quadro de desemprego estrutural. Restam, como alternativas para os trabalhadores, as soluções individuais, como a abertura de negócios próprios e o empreendedorismo.

\section{Considerações finais}

Nas nossas reflexões, procuramos problematizar as ações da qualificação profissional desenvolvidas nos APLs de Confecções do Agreste de Pernambuco como uma estratégia ídeo-política que sustenta o discurso neodesenvolvimentista, amplamente massificado nos últimos governos brasileiros. Estas ações têm como cimento a condição de trabalho precário, informal e superexplorado. Contudo, aparecem de forma positiva como opção de inclusão produtiva para os trabalhadores, e são tratadas apologeticamente como iniciativas que visam formar empreendedores.

Apesar da propagação do discurso em torno da importância da difusão do conhecimento, nesta realidade o que pudemos observar é que existe uma massa de trabalhadores informais. Eles têm, no acesso ao conhecimento tácito e instrumental, a única opção de aprendizagem, ora por 


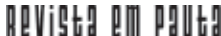

\} ARRANJOS PRODUTIVOS LOCAIS COMO ESTRATÉGIA NEODESENVOLVIMENTISTA - COSTA, F.; AMARAL, A. \} DOI: 10.12957/rep.2015.21050

não terem possibilidade de ações mais sistemáticas de qualificação profissional, as quais, na sua maioria, são direcionadas aos trabalhadores formais ou com maior poder aquisitivo - os que podem comprar esse serviço no mercado -; ora porque as condições objetivas de trabalho não permitem que estes trabalhadores destinem parte do seu tempo de produção para a ampliação de conhecimentos mais abrangentes e numa perspectiva integral.

O desenvolvimento de novos aprendizados e a difusão de inovações tecnológicas são restritos a um nicho de trabalhadores, os quais, além de pouco influenciarem na organização do processo produtivo, devem buscar individualmente as condições de sua empregabilidade para se manter nas empresas formalizadas.

Algumas outras questões identificadas na maior parte das cidades que compõem o Polo de Confecções são relevantes para entender a incompatibilidade entre crescimento econômico e desenvolvimento social: a baixa escolaridade da população local; a ausência de planejamento por parte do poder público, no sentido de oferecer suporte ao desenvolvimento econômico e social; e a precária oferta de serviços sociais e equipamentos públicos. Estes são, a nosso ver, a expressão de que, por mais que a qualificação profissional seja ampliada e massificada, e obedeça ao princípio de articulação com "atores locais", ao qual se refere o Sebrae, ela não tem o caráter salvacionista. Na realidade, ela mais parece se constituir numa saída para acomodar parte da força de trabalho que, em função da crise capitalista, integra as fileiras da superpopulação relativa.

Em nossa análise sobre esse processo, na realidade pesquisada, pudemos identificar um discurso que enfoca a importância atribuída ao conhecimento, conferindo-lhe uma perspectiva salvacionista como forma de enfrentar o quadro de desemprego estrutural e propiciar a inclusão produtiva, sob quaisquer condições.

Ao imprimir às ações de qualificação profissional o fundamento ideológico do empreendedorismo, compreendido como sinônimo de liberdade, propriedade, autonomia e independência, tenta-se escamotear a condição de direito ao trabalho protegido. Assim, molecularmente vai se construindo o consenso em torno dessa ideia como algo positivo para os trabaIhadores e como horizonte prático e político para essa classe, projeto esse que tem a anuência do Estado. Como já afirmamos, esse direcionamento faz parte das estratégias capitalistas para manter sua hegemonia, conformando, a partir de seus aparelhos privados de hegemonia, e com o apoio do Estado educador, uma ideologia em consonância com seus interesses.

O processo de construção de consensos tem se concretizado através de diversas formas, sendo a qualificação dos trabalhadores uma das mais estratégicas, pois tem a potencialidade de adequar a força de trabalho às necessidades capitalistas. Por essa via, é conformada uma nova cultura do trabalho, que repõe o ethos do trabalho sob novas bases: flexibilizadas, precárias e destituídas de valores coletivos e ético-políticos. 


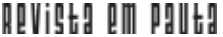

\} ARRANJOS PRODUTIVOS LOCAIS COMO ESTRATÉGIA NEODESENVOLVIMENTISTA - COSTA, F.; AMARAL, A. \}

DOI: $10.12957 /$ rep.2015.21050

Trata-se, portanto, de uma construção que atualiza as formas de domínio do capital sobre o trabalho e requerem a socialização de novos valores políticos, sociais e éticos, bem como a produção de comportamentos compatíveis com as necessidades de mudança na esfera da produção e na reprodução social (MOTA; AMARAL, 1998).

Por fim, podemos afirmar que a formação de uma nova cultura do trabalho nos APLs de Confecções do Agreste Pernambucano, através da qualificação profissional, incorpora as necessidades contemporâneas do processo de acumulação capitalista às estratégias neodesenvolvimentistas que marcam os governos Lula da Silva e Dilma Rousseff. Visa, portanto, à formação de um trabalhador adaptado àquelas necessidades, objetiva e subjetivamente, buscando sua adesão e o seu consentimento às exigências capitalistas. 


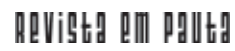

\} ARRANJOS PRODUTIVOS LOCAIS COMO ESTRATÉGIA NEODESENVOLVIMENTISTA - COSTA, F.; AMARAL, A. \} DOI: $10.12957 /$ rep.2015.21050

\section{Referências}

AMARAL, A. S. Qualificação dos trabalhadores e estratégia de hegemonia: o embate de projetos classistas. Tese (Doutorado em Serviço Social) - Escola de Serviço Social, Universidade Federal do Rio de Janeiro, Rio de Janeiro. 2005.

ARAúJO, T. B. Por uma política nacional de desenvolvimento regional. Revista Econômica do Nordeste, Banco do Nordeste, v. 30, n. 2, abr./jun. 1999. Disponível em: <http://www.bnb.gov.br/projwebren/Exec/ artigoRenPDF.aspx?cd_artigo_ren=143>. Acesso em: 20 dez. 2011.

BRASIL. Política Nacional de Desenvolvimento Regional. 2007. Disponível em: <http://www.mi.gov.br/desenvolvimentoregional/pndr/>. Acesso em: 3 mar. 2012.

CARCANHOLO, M. D. Dependência e superexploração da força de trabalho no desenvolvimento periférico. In: MARTINS, C. E.; VALENCIA, A. S. A América Latina e os desafios da globalização: ensaios dedicados a Ruy Mauro Marini. São Paulo: Boitempo. 2005.

CARVALHO, C. P. de O. Nordeste: sinais de um novo padrão de crescimento (2000/2008). 2008. Disponível em: <http://www.anpec.org.br/encon tro2008/artigos/200807211223330-.pdf>. Acesso em: 20 dez. 2011.

CONDEPE/FIDEM. PIB pernambucano cresceu 3,2\% no segundo trimestre de 2013. 2013. Disponível em: <http://www2.condepefidem.pe.gov.br/ web/condepe-fidem/exibir_noticia?groupld=19941 \&articleld=8328297 \&templateld=82535>. Acesso em: 25 jan. 2014.

COSTA, F. M. Trabalho e qualificação profissional no arranjo produtivo local de confecções do Agreste de Pernambuco: a experiência de Toritama. Dissertação (Mestrado) - Programa de Pós-Graduação em Serviço Social, Universidade Federal de Pernambuco, Recife. 2012.

COUTINHO, C. N. Gramsci: um estudo sobre seu pensamento político. Rio de Janeiro: Civilização Brasileira. 2003.

D'ARAúJO, M. C. Capital social. Rio de Janeiro: Zahar Editora. 2003.

FRIGOTTO, G. Educação e a crise do capitalismo real. São Paulo: Cortez. 1995.

. Educação, crise do trabalho assalariado e do desenvolvimento: teorias em conflito. In: FRIGOTTO, G. (org.). Educação e crise do trabalho: perspectivas de final de século. Petrópolis: Vozes. 1996.

GRAMSCI, Antonio. Obras escolhidas. São Paulo: Martins Fontes, 1978.

IBGE. Instituto Brasileiro de Geografia e Estatística. Síntese de indicadores sociais: uma análise das condições de vida da população brasileira. Estudos e Pesquisas: informação demográfica e socioeconômica, n. 29. 2012. 


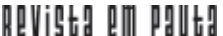

\} ARRANJOS PRODUTIVOS LOCAIS COMO ESTRATÉGIA NEODESENVOLVIMENTISTA - COSTA, F.; AMARAL, A. \} DOI: 10.12957/rep.2015.21050

MARINI, R. M. Dialética da dependência. In: TRASPADINI, R.; STÉDILE, J. P. (org.). Ruy Mauro Marini: vida e obra. São Paulo: Expressão Popular. 2005.

MARX, K. O capital: crítica da economia política. Livro 1: o processo de produção do capital, vol. 1. Rio de Janeiro: Civilização Brasileira. 1980.

MÉSZÁROS, I. A educação para além do capital. São Paulo: Boitempo. 2008. MOTA, A. E. Cultura da crise e seguridade social: um estudo sobre as tendên-ias da previdência e da assistência social brasileira nos anos 80 e 90 . São Paulo: Cortez, 2000.

MOTA, A. E.; AMARAL, A. S. Reestruturação do capital, fragmentação do trabalho e Serviço Social. In: MOTA, A. E. A nova fábrica de consensos. São Paulo: Cortez. 1998.

MOTA, A. E.; AMARAL, A. S.; PERUZZO, J. F. O novo desenvolvimentismo e as políticas sociais na América Latina. As ideologias da contrarreforma e o Serviço Social. Recife: Editora Universitária da UFPE. 2010.

NEVES, L. M. W.; PRONKO, M. A. O mercado do conhecimento e o conhecimento para o mercado: da formação para o trabalho complexo no Brasil contemporâneo. Rio de Janeiro: Escola de Saúde Joaquim Venâncio/Fundação Oswaldo Cruz. 2008.

OLIVEIRA, F. Elegia para uma Re(li)gião. Rio de Janeiro: Paz e Ter-ra, 1977.

REDESIST. Arranjos produtivos locais no estado de Pernambuco: mapeamento, metodologia de identificação e critérios de seleção para políticas de apoio. Nota técnica 02. Projeto Análise do Mapeamento e das Políticas para Arranjos Produtivos Locais no Norte, Nordeste e Mato Grosso e dos Impactos dos Grandes Projetos Federais no Nordeste, Pernambuco. 2010. Disponível em: <http:// http://www.redesist.ie.ufrj.br/>. Acesso em: 15 mar. 2012.

SEBRAE. Estudo econômico do arranjo produtivo local de confecções do Agreste Pernambucano. Relatório Final. 2012.

TAVARES, M. A. Os fios invisíveis da produção capitalista: informalidade e precarização do trabalho. São Paulo: Cortez. 2004.

. O trabalho informal e suas funções sociais. Revista Praia Vermelha, Rio de Janeiro, v. 20, n. 1, jan./jun. 2010.

UDERMAN, S. O Estado e a formulação de políticas de desenvolvimento regional. Revista Econômica do Nordeste, Fortaleza, v. 39, n. 2, abr./jun. 2008. Disponível em: <http://www.bnb.gov.br/projwebren/exec/artigo RenPDF.aspx?cd_artigo_ren=1081>. Acesso em: 17 mar. 2012.

URANI, A.; COCCO, G.; SILVA, M. C. P. da. Desenvolvimento local e espaço público na Terceira Itália: questões para a realidade brasileira. In: URANI, 


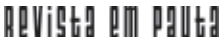

\} ARRANJOS PRODUTIVOS LOCAIS COMO ESTRATÉGIA NEODESENVOLVIMENTISTA - COSTA, F.; AMARAL, A. \} DOI: 10.12957/rep.2015.21050

Recebido em 31 de julho de 2015.

Aprovado para publicação em 09 de dezembro de 2015.

DOI: 10.12957/rep.2015.21050

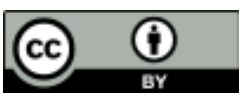

A Revista Em Pauta: Teoria Social e Realidade Contemporânea está licenciada com uma Licença Creative Commons Atribuição 4.0 Internacional.

EM PAUTA, Rio de Janeiro - $2^{\circ}$ Semestre de 2015- n. 36, v. 13, p. 17 - 42 